\title{
On the effect of autumn treatment of soils with humic acid preparations on soil biological fertility and yield in the German agriculture
}

Nowick W. ${ }^{1}$, Semeniuk I. ${ }^{2}$, Karpenko E. ${ }^{2}$, lutynska G. ${ }^{3}$, Yamborko N. ${ }^{3}$

${ }^{1}$ daRostim Private Institute of Applied Biotechnology, Waldheim, Germany, info@darostim.de

${ }^{2}$ Department of Physical Chemistry of Fossil Fuels InPOCC, NAS Ukraine, Lviv, igorsem777@gmail.com

${ }^{3}$ Institute of Microbiology and Virology, NAS Ukraine, Kiew, iutynska@mail.ru

Keywords: humic preparations, phytohormone-humic compositions, biological indicators of the soil

doi: 10.36291/HIT.2019.nowick.122

As part of the international long-term program Tandem ${ }^{12 / 21}$ (2012-2021) we investigated changes in the microbiological parameters of the soil at different locations (soil index 27 to 67) through the application of various phytohormone-humic acid (PHC) composites. PHCs applied in the spring during the spring stimulated photosynthesis and contributed to the improvement of the biological parameters of the soil.. In order to intensify the conversion of organic material into humus and to stabilize these indicators in winter, the experimental fields were treated after harvest with PHCs (autumn treatment - AT) [1].

The results of the monitoring of soil biology and yield increases showed additional effects of a systematic AT. The averages were compared between 2012-2018 with additional AT with the 2006-2011 control period. The AT resulted in a new biological equilibrium in the soil with a 47 to $89 \%$ higher concentration of the air nitrogen-binding (N) and phosphorus-mobilizing $(P)$ bacteria relevant for biological plant nutrition. Yield increases of 6.6 to $7.7 \mathrm{GE}(10$ to $22 \%)$ were achieved with the same or even lower $\mathrm{N}$ fertilizer use. The efficiency of the $\mathrm{N}$ fertilizer used in relation to the yield $(\mathrm{Y} / \mathrm{N})$ increased by 10 to $40 \%$.
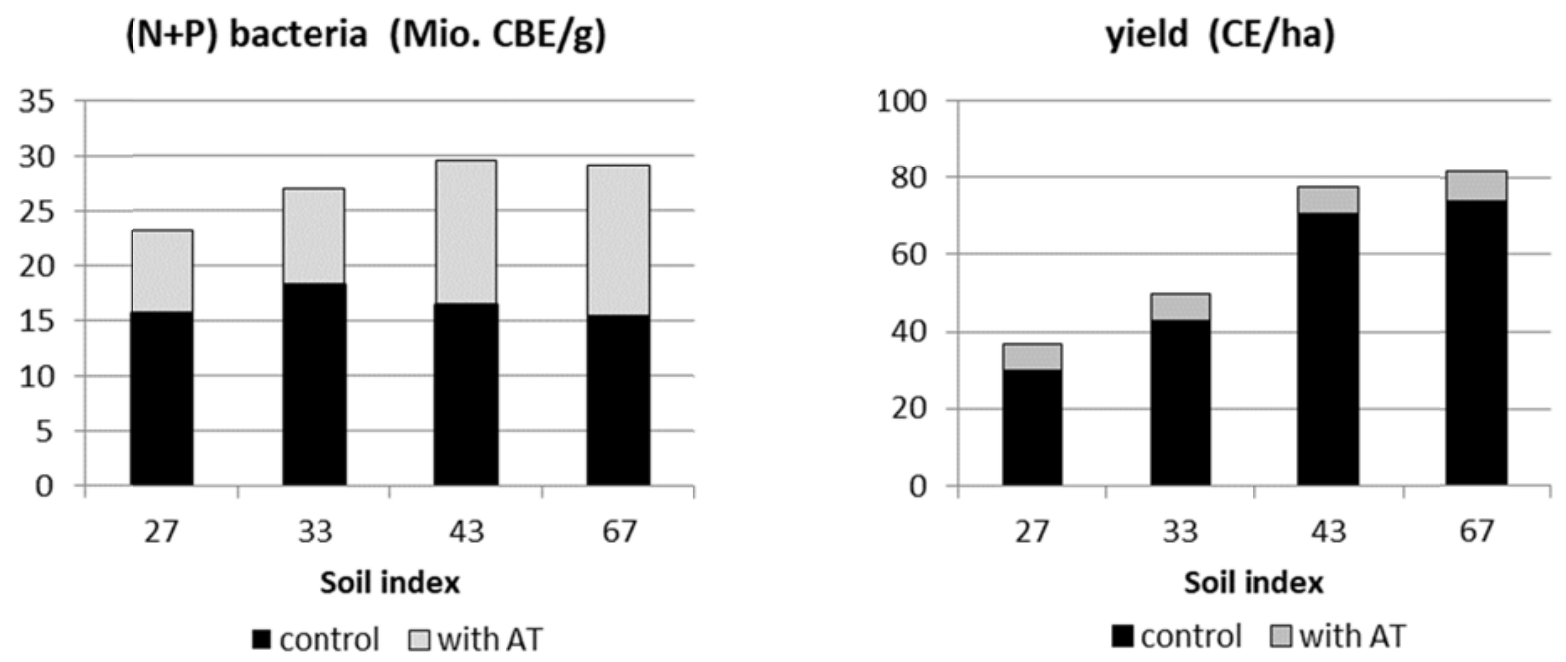

Figure 1, 2. Effect of autumn treatment on biological soil fertility and yield at different sites (average values: control: 2006-2011, AT: 2012-2018)

References

1. Nowick W. et al. // In: XII International scientific-applied conference daRostim, Odessa 2016, Ukraine, Proceedings, p.173-177. 